\title{
Sexuality and school: dynamics of this relationship in the perspective of teenagers
}

\begin{abstract}
Analyze from the students which outlines adopted by the school and in the classroom, regarding the theme of sexuality. Held in State College Misael Aguilar Silva, in Juazeiro-Bahia, with 79 teenagers elementary and middle II. Data were analyzed in Excel 2007/2010. Approved by the Ethics Committee, under No.0014/250614. Of the students, $34 \%$ report that it is little worked in school. The school environment occupied a position of not promoting critical and reflective actions and transdisciplinary approach in the treatment of the subject in the classroom. It will be important to integrate and bring the young for a more effective dialogue in order to ease the lack of knowledge, fears and taboos about sexuality.
\end{abstract}

Keywords: teens, education, sexuality

\author{
Volume 3 Issue 4 - 2017 \\ Mônica Cecília Pimentel de Melo,' Isabella \\ Mendes Gomes, ${ }^{2}$ Gustavo Elias da Silva, ${ }^{2}$ \\ Albertino José Ferreira Neto, ${ }^{2}$ Jessica Lopes \\ Gomes, ${ }^{2}$ Eduardo Montenegro Dutra, ${ }^{2}$ Keylla \\ Karinna Marques, ${ }^{2}$ Félix Alexandre Antunes \\ Soares ${ }^{3}$ \\ 'Enfermeira, Doutoranda em Educação em Ciências com \\ Associação de IES UFRGS/UFSM/FURG, Brazil \\ ${ }^{2}$ Graduanda em Medicina pela UNIVASF. Petrolina, Brazil \\ ${ }^{3}$ Bioquímico, Doutor em Ciências Biológicas, Docente pela \\ UFSM, Santa Maria, USA
}

\begin{abstract}
Correspondence: Mônica Cecília Pimentel de Melo, Enfermeira, Doutoranda em Educação em Ciências com Associação de IES UFRGS/UFSM/FURG, Brazil, Email monquinamelo@gmail.com
\end{abstract}

Received: May 16, 2017 | Published: August 18, 2017

\section{Introduction}

The experience of sexuality encompasses all stages of the life of men and women, beginning with the birth and lasting until death (BRAZIL, 2010b). To do so, it is in adolescence that the exercise of sexuality contributes to the structuring of the identity of the young person, being often driven by their peers or by the use of psychoactive substances, by means of communication and by sensations such as curiosity, Need for affection or independence, adolescents often act by incitement and engage in sexual activities, because at this stage sexuality has an exploratory function, discovering new potentialities and ways of giving it to the new body. ${ }^{1,2}$

Sexual issues and their nuances emerge in a notorious way as a reason for concern of parents, in that, because they do not know how to approach the issue with their children, or because they repeat the same conduct of their parents, of non-dialogue, they transmit to school Responsibility for indicating the ways to resolve taboos and controversial topics, such as that of sexuality in this phase of life. This fact, the school is a locus of actions of promotion to the health of the adolescent in which the subject sexuality can be treated of more natural and propitious way. In this respect, information can become more solid when they leave the teacher in the classroom, in particular, the teachers of biology, because they deal with contents that are closer to the thematic sexuality, in which body - anatomy and human physiology; Transformations of this body - puberty and vulnerabilities - sexually transmitted diseases, pregnancy, abortion. At this juncture, other disciplines of the school context can also work transversally parallel themes to the sexuality of young people and adolescents.

Since 1996, innovative actions have already been discussed in school curricula with proposals that allow the introduction of themes such as sexual and reproductive education of adolescents in the most diverse age groups, under the aegis of democratic principles, with a focus on dignity, equality Rights, participation and co-responsibilities. Therefore, the National Curricular Parameters (NCPs), elaborated by the Ministry of Education, propose to work on the theme of sexuality in a transversal way and in any discipline. ${ }^{3,4}$ Still permeated by approaches to change, the school, over the years, in order to integrate education and health, has become the target of actions of programs and policies aimed at adolescents, through the implementation of the National Policy of Comprehensive Health Care of Young Adolescents and the School Health Program (PSE) as guiding axes that support actions directed to the issue of sexuality in schools. ${ }^{5}$

Accountability for the dialogue of themes such as sexuality in adolescence should be a banner of struggle of the most varied spaces of the adolescent's life, permeating, in increasing degrees of importance by family, school, media, religion, etc. Therefore, the relevance and contribution of this study is social and academic, since as the school plays a fundamental role in the sexual and reproductive health and education of adolescents, its position must be committed not only to pass on information, but to make the adolescent agent Of his own change of behavior, valuing him as an active subject of his knowledge, peculiarities and experiences.

Therefore, assuming that the school has a fertile field of discussions and practices of actions in health promotion and vulnerability prevention, including there, the paradigm break that values the dialogue between teachers and students about sex education and the transversality of the theme In all the disciplines worked, the following study object was highlighted: dynamics of the relation adolescence, sexuality and school. Thus, it is a question of research: what are the dynamics adopted by the school in the dialogue about sexuality with students, from the perspective of adolescents? In this conjuncture it presents itself as an objective: to analyze from the students the delineations adopted by the school and in the classroom, in what concerns the theme sexuality. 


\section{Methodology}

This is a quantitative, cross-sectional exploratory and descriptive research. The project was developed in the city of Juazeiro, State of Bahia, at the Misael Aguilar Silva State College (CEMAS), located in the D. José Rodrigues neighborhood.

The study collaborators were 79 adolescent students, from the 03 school shifts, minors and/or over 18, elementary and secondary education. As eligibility criteria listed for their participation in the study, it was established: to be adolescent, in the age group recommended by the World Health Organization (WHO) and Ministry of Health (MS)10 to 19 years; to be attending primary and secondary education. Data collection comprised the period from November to December 2014 , on dates pre-established with the board, during class, in a collective manner. A questionnaire structured and standardized by the researchers was applied to the students, self-fulfilling and unidentifiable, composed of closed-ended and multiple-choice questions. This conduction occurred through the voluntary adhesion of adolescent students duly enrolled in their school unit. For the application of the questionnaire to the absent students, the researchers returned to school two to three subsequent times.

Data were stored in an information bank created in Microsoft Excel ${ }^{\circledR} 2007 / 2010$, using descriptive statistics for the percentage distribution of all variables considered important, whose results were presented in tables. The beginning of the collection occurred only after authorization from the State College Misael Aguilar Silva and approval of the research by the Ethics and Deontology Committee on Studies and Research (CEDEP) of the Federal University of the São Francisco Valley (UNIVASF), under protocol no. 0014/250614.

\section{Results and discussion}

The analysis of the results showed that of the 79 students that composed the sample, $67 \%$ were female and $33 \%$ male, distributed by age according to Table 1 . The study encompassed all the ages sought, between 10 and 19 years that make up, according to the WHO, the classification of adolescence. There was no predominance of age, but a more equitable distribution of age groups. That said, thinking about sexuality in adolescence requires an observation about the different senses that the discoveries and the changes, at this stage of life, exert on the genera, considering the time, place and age in which the phenomenon occurs. ${ }^{6}$ It is on these aspects that culture starts to determine different social practices and lifestyles for the ages, in a differentiated way, since the education aimed at a student of 10 years is different for a 19 -year-old adolescent, which makes it impossible to analyze a small age group, requiring all of them to compose satisfactory results and discussions. ${ }^{7}$ When asked about whether they talk to someone about sexuality, $89 \%$ of the students said that they talk, and as for the people who the teenagers talk about, a grade ranging from 0 to 10 was scored, considering 0 as "I do not convert at all About anything related to sexuality "and 10 as" I am free to talk about any topic related to sexuality ", obtaining the following averages. In the incessant search for information, stemming from the intrinsic curiosity of this phase of life, adolescents obtain elements about sexuality from formal and informal sources, because they are exposed to diverse social and cultural influences that lead such young people to grasp the subject in a generalized way. ${ }^{8}$

As shown in Table 2, the search for dialogue is more concentrated in the interlocutors of the family and social life of adolescents, such as: friends, mother and boyfriend, not being observed the same frequency in dialogues with teachers and Health professionals. Other studies on the subject also suggest an increase in adolescents' dialogue with their parents, especially with the mother, but such conversations appear to be superficial, often due to the shame and technical ignorance of the subject by the parents. ${ }^{6}$ Dialogues with friends, the main interlocutors, according to Table 2, were more frequent. However, due to the very inexperience and possible immaturity of the approaches have their validity and seriousness of contents put in doubt. ${ }^{6}$

Table I Distribution of students by age. Juazeiro-BA/Brazil, 2014

\begin{tabular}{ll}
\hline AGE & $\%$ Students \\
\hline 10 & $1 \%$ \\
11 & $4 \%$ \\
12 & $5 \%$ \\
13 & $20 \%$ \\
14 & $13 \%$ \\
15 & $5 \%$ \\
16 & $15 \%$ \\
17 & $14 \%$ \\
18 & $16 \%$ \\
19 & $6 \%$
\end{tabular}

Table 2 Average points with which adolescents talk about sexuality. JuazeiroBA/Brazil, 2014

\begin{tabular}{ll}
\hline With whom conversation on sexuality & Average points \\
\hline Religious Group & 0,23 \\
Father & 1,56 \\
Uncles & 2,07 \\
Brothers and sisters & 2,24 \\
Health professionals & 2,37 \\
Teacher & 2,54 \\
Cousins & 3,44 \\
In a relationship & 4,69 \\
Mother & 5,20 \\
Friends & 5,97 \\
\hline
\end{tabular}

Regarding teachers and health professionals, there is a relative distancing of adolescents in relation to these, although theoretically they are the holders of the most formal and systematized knowledge of the subject in question. Thus, it is necessary to improve the actions of educators and health professionals, integrating and bringing the young person closer to a more effective, welcoming, dialogical and stereotype-free dialogue. ${ }^{7}$

When asked about the source in which they seek information about sexuality, the students assigned a grade of 0 (minimum grade) to 10 (maximum grade), obtaining the following averages by means of information. The internet was evidenced as the largest holder of the average of points, which generates concern, since it is given great 
importance to the theme in the virtual environment, as well as in the television - source of information important in the study, although the majority of the programs or sites are not structured to promote quality information. ${ }^{8}$ Another analysis obtained from the data in Table 3 is the small information search in religion, pointing out that it exerts little influence, not being a determining factor in obtaining data that will support the sexuality of adolescents.

Table 3 Source of information on sexuality. Juazeiro-BA/Brazil, 2014

\begin{tabular}{ll}
\hline Where to look for sexuality information & Average points \\
\hline Church & 1,27 \\
Newspaper & 1,73 \\
Magazines & 2,62 \\
Soap operas & 3,10 \\
TV shows & 3,28 \\
School & 3,52 \\
Movies & 3,52 \\
My Account & 3,66 \\
Internet & 4,95 \\
\hline
\end{tabular}

It is the role of the school, to offer a complement in the citizen's education of the young person on sexual and reproductive education, continuing a discussion that should have its beginning in the family, but that for reasons, often, of constraints, by both parties, both of the Family, as well as the adolescent's, the school ends up performing the function that alone should be shared by other instances - family, health units, media, religion, etc. ${ }^{9}$ In this way, the research revealed the importance of the school in addressing sub-themes related to sexual and reproductive education, in the daily classroom, according to Table 4, as a way for students to acquire more knowledge about the subject.

Table 4 Reasons for the school to develop sex education activities. JuazeiroBA/Brazil, 2014

\begin{tabular}{ll}
\hline $\begin{array}{l}\text { Why the school must develop activities } \\
\text { in sex education }\end{array}$ & \% Answers \\
\hline Pleasant & $2 \%$ \\
Tabu & $2 \%$ \\
important & $30 \%$ \\
Knowledge & $65 \%$ \\
\hline
\end{tabular}

Knowledge is the key to a safe sexual practice, as well as an indispensable tool in the construction of responsible positions when the subject involves use of contraceptive methods; Maternity and paternity; Respect to sexual choices; Egalitarian gender relations; Among others. ${ }^{9}$ As adolescents spend much of their time in school, it is the main source of knowledge for strengthening assertive decisions. Therefore, there is nothing more natural that the responsibility for this informational role should be sought in school. Therefore, in the relation on how the thematic sexuality in the school is treated, the students answered.

The main institution of coexistence of the adolescent is still the family. It is through this that, initially, information and knowledge about the specificities of human life are acquired. In this tenuous continuity comes to the school, in which many adolescents will begin to acquire more knowledge, among them, knowledge related to sexual and reproductive education. However, according to Table 5, the data most frequently mentioned by the students is that the subject is little worked in the school and when its discussion is opportunistic, it happens predominantly in the discipline of biology/science Table 6 .

Table 5 Form that thematic sexuality is treated in the school. Juazeiro-BA/ Brazil, 2014

\begin{tabular}{ll}
\hline How the sexuality theme is treated at school & $\%$ Answers \\
\hline The school does not need to & $4 \%$ \\
Very well worked & $15 \%$ \\
Not worked & $18 \%$ \\
I would like more moments in school & $29 \%$ \\
Little worked & $34 \%$ \\
\hline
\end{tabular}

Table 6 Form that the school has provided information about sexuality Juazeiro-BA/Brazil, 2014

\begin{tabular}{ll}
\hline How The School Provides Information on Sexuality & $\%$ Answers \\
\hline There are always lectures at school & $8 \%$ \\
Through another discipline & $12 \%$ \\
Sometimes there are lectures at school & $30 \%$ \\
Through the discipline of Biology / Sciences & $50 \%$ \\
\hline
\end{tabular}

According to Art. 16 of Resolution CNE/CEB No.4/2010, which defines the General National Curricular Guidelines for Basic Education, curricular components and areas of knowledge, must articulate in their contents, based on the possibilities opened by their reference points, The approach to comprehensive and contemporary themes that affect human life. Thus, subjects such as sexuality in adolescence should be approached by schools in their pedagogical projects and in the classroom, in a transdisciplinary way, spanning all disciplines. ${ }^{10}$ In this way, it is evident the need for sexual education measures in schools, not only through Biology/Sciences teachers, but also of all other educators, as well as health professionals and family members, using attractive, not so systematic means, Giving dialogic opportunities for discussion. Group techniques such as workshops, lectures, use of playful and pedagogical means and the problem-solving methodology, proposed by Paulo Freire, are ways in which teachers and managers can use, as it allows the construction of knowledge from experiences, information and. ${ }^{9,11}$ In this paper, we present the results of the study of the literature on the subject. Some studies make evident the lack of information and the discomfort of some teachers of subjects that are not those of Biology/Sciences to deal with the subject. In this way, some aspects such as the lack of training to improve their knowledge, and thus, to approach the subject in a more didactic way, respecting the age groups. ${ }^{10}$ Therefore, in addition to the subject being little discussed in the school, restricting itself, in most cases, to the discussion within the discipline of biology/ sciences, the students present many doubts, mainly, related to the controversial subthemes of sexuality, being Table 7 .

All these themes are already pointed out by the NCP, thus focusing on the need for important interventions in the daily life of sexual and reproductive education in schools. ${ }^{12-14}$ It is worth mentioning that some important events, such as the birth of the contraceptive pill, 
changes in the socio-cultural standards attributed to women, marriage and female sexuality, besides the advent of AIDS, have increasingly raised doubts and questions among adolescents About sexuality and its current patterns.

Table 7 Subjects of the topic of sexuality that students would like the schoo to talk more. Juazeiro-BA/Brazil, 2014

\begin{tabular}{ll}
\hline Subjects that would like school to converse more & $\%$ Answers \\
\hline Others & $1 \%$ \\
Masturbation & $5 \%$ \\
Homosexuality & $6 \%$ \\
Condom use (male and female) & $7 \%$ \\
Anabolics and other drugs & $8 \%$ \\
Pregnancy & $8 \%$ \\
Contraceptive methods & $8 \%$ \\
SexualViolence & $8 \%$ \\
Abortion & $9 \%$ \\
Body hygiene and sexual intercourse & $9 \%$ \\
Menstruation and body care & $10 \%$ \\
Transformations in the body of the adolescent & $10 \%$ \\
AIDS and other STDs & $11 \%$ \\
\hline
\end{tabular}

Obviously, with the technological accessibility that we have today, it is concluded that it is not the lack of access to information, but the precariousness in understanding sexuality and its nuances that compromise the preventive aspects for the exercise of a safer and responsible sexuality. The results pointed out the dilemmas and anxieties faced by adolescents who are exposed to a media that does not clarify satisfactorily and ends up inciting the banalization of sexual content, and the family and teachers should act as reliable equalizers of these questions, always Body dimensions, gender and prevention of physical, emotional and social damages. Therefore, it is clear that the school needs to establish partnerships for the promotion of teacher training so that they can feel more secure and take responsibility for discussing the subject as a cross-cutting theme that permeates all the disciplines of the school system.

\section{Conclusion}

The present study made it possible to reflect that the dynamics of the relationship between adolescents and the school, regarding Sexuality in Adolescence, is still permeated by a relationship that does not promote the discussion of sexual and reproductive education, and when it is discussed, it is something which is often restricted only to pubertal and reproductive system modifications. Therefore, the design adopted by the school occupied a non-promoting position of criticalreflexive actions and a transdisciplinary approach, which leads to a lack of sustainability between education, adolescence and sexuality, in times of public policies and programs that value the insertion of health Prevention and care in the school environment.

Adolescence itself is already a phase of discoveries, new sensations, curiosities and nothing is more natural than the will of the teenager himself in trying to discover and understand this huge range of modifications and novelties. To this end, improvements are needed in how to deal with the issue with educators and students, integrating and bringing the youth closer to a more effective dialogue in order to alleviate the lack of knowledge, fears and taboos, given that it is indispensable to the insertion And interlocution among family, educators, health professionals and the media, providing the necessary support in this difficult task in discussing taboos topics related to adolescent sexual and reproductive health.

\section{Acknowledgements}

None.

\section{Conflict of interest}

The author declares no conflict of interest.

\section{References}

1. Martinez MCW. dolescence - sexuality-aids: in the contemporary family and school space. Art \& Science. Brazil: São Paulo;1998. p. 21-47.

2. Oliveira DC, Antônio Marcos Tosoli Gomes, Ana Paula Munhen de Pontes, et al. Attitudes, feelings and images in the social representation of sexuality among adolescents. Anna Nery School Nursing Journal, Rio de Janeiro. 2009;13(4):817-823.

3. Brazil LDB: Law of guidelines and bases of national education: Law No. 9,394, of December 20, 1996, which establishes the guidelines and bases of national education. House of Representatives, Coordination Edições Câmara. $64 \mathrm{p}$

4. ECOS. Studies and Communication in sexuality and human reproduction. MacArthur foundation. Pólis Institute. Promote sex education in schools. Newsletter Tips, ideas for municipal action. Brazil: São Paulo; 2001;182:2

5. Ministry of health. Secretariat of health care, Department of basic attention. Instructional PSE/Ministry of health. Step by step PSE health program in school, weaving paths of intersectoriality. Brasília: Ministry of Health. 2011. 27 p

6. Romero KT. The knowledge of adolescents about issues related to sex. Journal of the Brazilian Medical Association. 2007;53(1):14-19.

7. Cedaro JJ, Vilas Boas LMS, Martins RM. Adolescence and sexuality: an exploratory study in a school in porto velho - RO. psychology. Science and profession. Brasília. 2012;32(2).

8. Marola CAG, Sanches CSM, Cardoso LM. Formation of concepts in sexuality in adolescence and its influences. Educational psychology. São Paulo. 2011;33:95-118.

9. Nau A, Saimon Boca Santa, Ivonete Teresinha Buss Heidemann, Maria da Glória Moura, et al. Sexual education of adolescents in the Freirean perspective through cultural circles. Journal of the Nursing Network of the Northeast Fortaleza. 2013;14(5):886-893.

10. Holanda ML. The role of the teacher in the sexual education of adolescents. Cogitare Nursing. 2010;15(4):702-708.

11. Freire P. Pedagogy of autonomy: knowledge necessary for educational practice. Journal of Nursing UFPE on line. 1996;7(4)

12. Secretariat of Basic Education. National curricular parameters: Crosscutting themes: sexual orientation. Brazil: Springer; 1998. p. 308-315.

13. Ministry of health. Secretariat of health care. Department of basic attention. Sexual health and reproductive health. Notebooks of Basic Attention, n. 26. Brasília: Ministry of Health. 2010. 300 p.

14. Gomes C. Group experience: sexuality, gender, adolescence and school space. APS Review: Primary Health Care. 2013;16(1):103-111. 